\title{
Simple Program to Investigate Hysteresis Damping Effect of Cross-Ties on Cables Vibration of Cable-Stayed Bridges
}

\author{
Panagis G. Papadopoulos, Andreas Diamantopoulos, Haris Xenidis, and Panos Lazaridis \\ Department of Civil Engineering, Aristotle University of Thessaloniki, 54124 Thessaloniki, Greece \\ Correspondence should be addressed to Panagis G. Papadopoulos, panaggpapad@yahoo.gr
}

Received 11 October 2011; Revised 21 March 2012; Accepted 24 March 2012

Academic Editor: Husam Najm

Copyright (C 2012 Panagis G. Papadopoulos et al. This is an open access article distributed under the Creative Commons Attribution License, which permits unrestricted use, distribution, and reproduction in any medium, provided the original work is properly cited.

\begin{abstract}
A short computer program, fully documented, is presented, for the step-by-step dynamic analysis of isolated cables or couples of parallel cables of a cable-stayed bridge, connected to each other and possibly with the deck of the bridge, by very thin pretensioned wires (cross-ties) and subjected to variation of their axial forces due to traffic or to successive pulses of a wind drag force. A simplified SDOF model, approximating the fundamental vibration mode, is adopted for every individual cable. The geometric nonlinearity of the cables is taken into account by their geometric stiffness, whereas the material nonlinearities of the cross-ties include compressive loosening, tensile yielding, and hysteresis stress-strain loops. Seven numerical experiments are performed. Based on them, it is observed that if two interconnected parallel cables have different dynamic characteristics, for example different lengths, thus different masses, weights, and geometric stiffnesses, too, or if one of them has a small additional mass, then a single pretensioned very thin wire, connecting them to each other and possibly with the deck of the bridge, proves effective in suppressing, by its hysteresis damping, the vibrations of the cables.
\end{abstract}

\section{Introduction}

The pretensioned cables in a typical cable-stayed bridge of medium size [1], as they are very long with a length of magnitude order $100 \mathrm{~m}$, and a pretension axial force of magnitude order $1000 \mathrm{kN}$, exhibit, perpendicularly to their axis, a very small geometric stiffness, corresponding to their fundamental vibration mode, of a magnitude order only $50 \mathrm{kN} / \mathrm{m}$. Also perpendicularly to their axis, they exhibit a very small intrinsic damping, due to their material internal friction. For the previous reasons, they are often subjected to large amplitude vibrations. And, if the external excitation is approximately periodic, with a period close to a natural period of the cable, for example, the fundamental one, then resonance may happen, and vibration amplitudes increase excessively and are maintained, with no significant reduction for a long time, unless special measures are taken.

Two usual reasons for the previous cable vibrations of cable-stayed bridges are the following.

(1) A pretensioned cable exhibits a sag under its selfweight. Because of traffic, the ends of the cable, on pylon and deck, are subject to a variation of their displacements; thus the elongation and axial force of the cable vary, which implies variation of its geometric stiffness, too, as well as variation of the sag of the cable. This vibration, due to variation of geometric stiffness, is called parametric excitation.

(2) The successive pulses of a wind pressure exert a drag force, perpendicularly to the vertical plane of cables, at one side of the bridge. The variation of this drag force causes vibration of the cables.

In [2], a complete description of the problem of cable vibrations of cable-stayed bridges is presented, as well as a state of the art of various types of dampers for cable vibrations (viscous dampers, cross-ties, and others), along with case studies of dampers on real bridges.

The viscous dampers, although widely mentioned in literature, present some problems: usually, they are installed at the ends of a cable, where they are not very helpful; it seems that their main role is a slight reduction of cable's length, thus a slight increase of its geometric stiffness. Rarely, they 


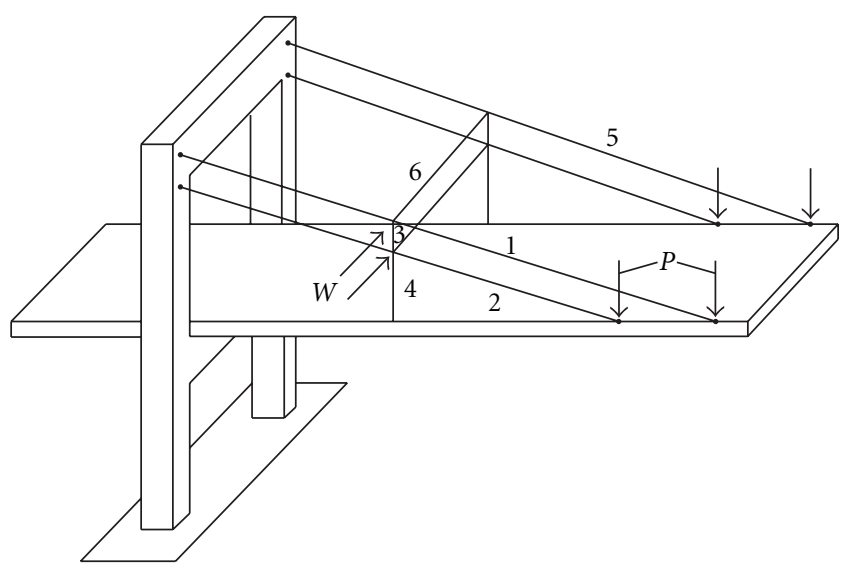

Figure 1: Part of a typical cable-stayed bridge [1].

are installed at intermediate points of a cable, where they are more helpful; however, this installation is difficult.

On the other hand, the cross-ties are preferable, for the following reasons: they are light and cheap, they are easily installed and pretensioned, and they easily replaced when damaged. And a great advantage of them is that although they are very thin, with a ratio of cross-section area of the cable to that of the cross-tie of a magnitude order 1000, however, the axial elastic stiffness, of a single pretensioned cross-tie, is comparable in magnitude with the geometric stiffness of a cable, that is of magnitude order $50 \mathrm{kN} / \mathrm{m}$, along the same direction, perpendicularly to cable axis. Also, as the cross-ties are very thin, they are almost invisible, so they do not harm the aesthetics of the bridge.

For the previous reasons, recently many researchers recommend the use of cross-ties to suppress large amplitude cable variations of cable-stayed bridges. In [3-6], analytical studies are performed on cross-ties or hybrid systems consisting of viscous dampers and cross-ties.

Here, a simplified analytical method is proposed [7], in order to investigate the hysteresis damping effect of crossties, where, for every individual cable, an SDOF model is adopted, approximating its fundamental vibration mode. The geometric nonlinearity of the cables is taken into account by their geometric stiffness. At same time, the proposed method is accurate, as it includes the material nonlinearities of the cross-ties, by their compressive loosening, tensile yielding, as well as hysteresis stress-strain loops.

A short computer program (only about 120 Fortran instructions), fully documented, is presented for the stepby-step dynamic analysis [9] of isolated cables or couples of parallel cables, connected to each other and possibly with the deck of the bridge, by very thin pretensioned wires (crossties) and subjected to variation of the axial forces of cables due to traffic [8] or to successive pulses of wind drag force.

Seven numerical experiments are performed. And, based on them, observations are made on the effectiveness of a single pretensioned very thin wire, connecting a couple of cables of a cable-stayed bridge, in suppressing, by its hysteresis damping, their large amplitude vibrations.

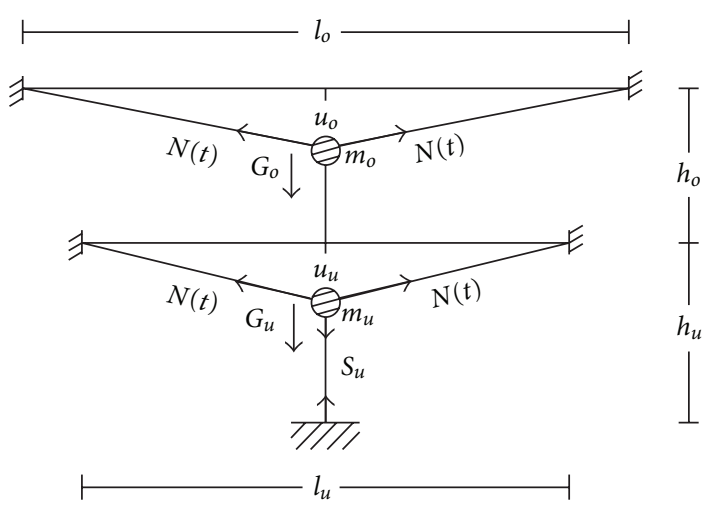

(a)

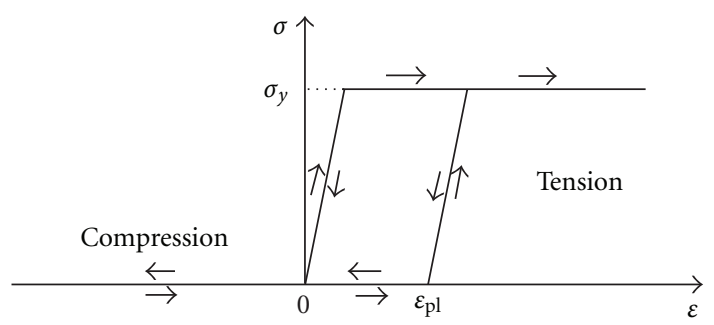

(b)

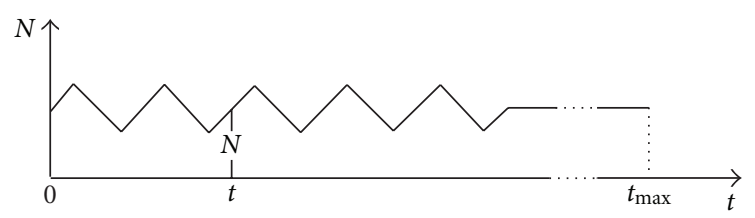

(c)

Figure 2: (a) Geometric, static, and dynamic parameters of a cable structure. (b) Primary $\sigma-\varepsilon$ diagram describing the nonlinear axial stress-strain law of a cross-tie. (c) Given time-history of axial forces of cables.

\section{Equations of the Problem}

Figure 1 shows a part of a typical cable-stayed bridge [1], with a pylon consisting of two vertical legs, which are connected by two transverse beams, a part of the deck with a slender rectangular plate section, two couples of pretensioned parallel inclined cables at each side of the bridge, connected by their ends to the pylon and the deck and two pretensioned very thin vertical in-plane cross-ties, at two sides of bridge, which intend to suppress parametric vibration of cables due to traffic loads $P$, as well as two outof-plane horizontal cross-ties, which intend to suppress cable vibrations due to wind forces $W$.

In the following, the equations of nonlinear dynamic analysis will be written, for a specific cable structure consisting of two parallel pretensioned cables ( 1 and 2 in Figure 1), connected by two very thin pretensioned crossties ( 3 and 4 in Figure 1) to each other and with the deck of the bridge and subjected to parametric vibration, due to traffic. In subsequent applications, by simple and obvious modifications of these equations, other cable structures 


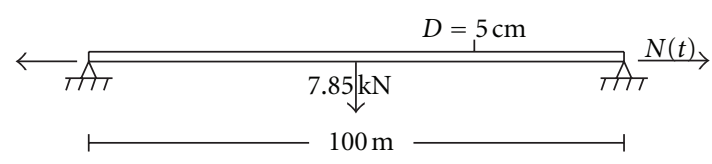

(a)

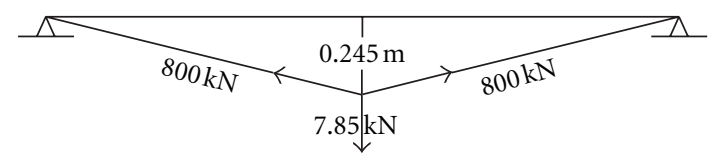

(c)

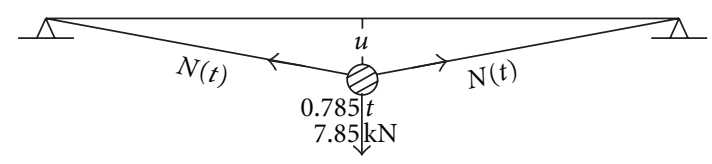

(d)

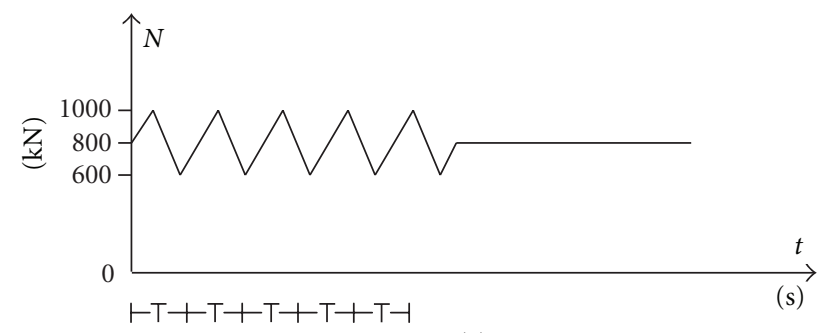

(e)

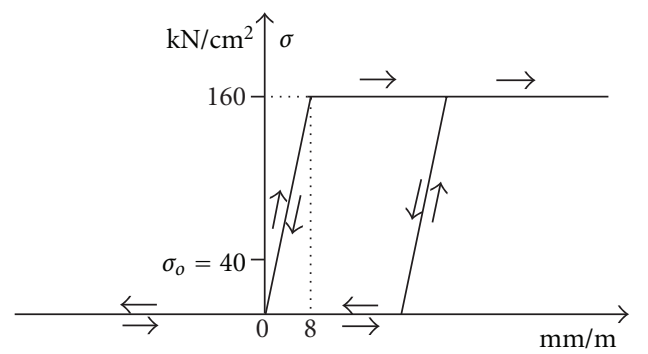

$E_{o}=2 \times 10^{4} \mathrm{kN} / \mathrm{cm}^{2}$

$\varepsilon_{F}=140 \mathrm{~mm} / \mathrm{m}$

$\rho=7.85 \mathrm{t} / \mathrm{m}^{3}$

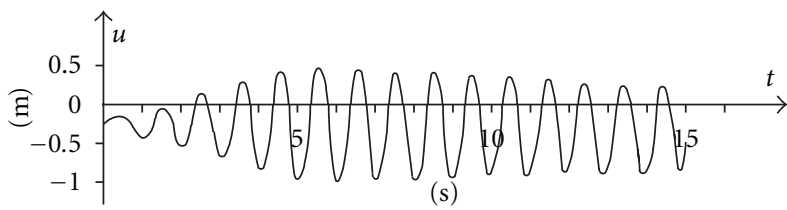

(f)

Figure 3: First application: isolated cable subject to traffic. (a) Given geometry and loading. (b) Axial stress-strain diagram of high-strength steel. (c) Initial static analysis. (d) Parameters of dynamic analysis. (e) Given time-history $N(t)$ of axial force of cable. (f) Resulting timehistory $u(t)$ of vertical displacement at center of cable.

(combinations of main cables and cross-ties) subjected to traffic or wind excitation will be treated, too.

In the following analysis, the inclination of the cables will be ignored for the sake of simplicity. So, in Figure 2(a), the couple of horizontal parallel pretensioned main cables represents the inclined cables 1 and 2 of Figure 1, whereas the very thin pretensioned vertical wires represent the in-plane cross-ties 3 and 4 of Figure 1.

2.1. Geometric Equations. For every individual cable, a simplified SDOF model is adopted, which approximates its fundamental vibration mode. This unique DOF, for every cable, is the displacement of its center perpendicularly to its axis, that is, the vertical displacements downwards $u_{o}$ and $u_{u}$ in Figure 2(a), for the upper and lower cables, respectively. The geometric equations, relating the displacements of cables with the elongations and strains of cross-ties, are the following, according to Figure 2(a):

$$
\begin{gathered}
\Delta h_{o}=h_{o}-u_{o}+u_{u}-h_{\mathrm{o} \varphi}, \\
\Delta h_{u}=h_{u}-u_{u}-h_{u \varphi},
\end{gathered}
$$

where $\Delta h_{o}$ and $\Delta h_{u}$ are elongations of upper and lower crossties, respectively, $h_{o}$ and $h_{u}$ their design (nominal) lengths, and $h_{\mathrm{O} \varphi}$ and $h_{u \varphi}$ are their initial undeformed lengths. And the strains $\varepsilon_{0}$ and $\varepsilon_{u}$ of upper and lower cross-ties, respectively, are

$$
\begin{aligned}
\varepsilon_{0} & =\frac{\Delta h_{o}}{h_{\mathrm{o \varphi}}}, \\
\varepsilon_{u} & =\frac{\Delta h_{u}}{h_{u \varphi}} .
\end{aligned}
$$

2.2. Constitutive Equations. Figure 2(b) is the primary stressstrain diagram, which describes the axial nonlinear stressstrain law of a cross-tie, made of the same high-strength steel as the main cables. This $\sigma-\varepsilon$ law includes compressive loosening, tensile yielding, as well as hysteresis stress-strain loops, resulting from the obvious in loading-unloading rule Figure 2(b). There is only one constitutive variable, the plastic strain $\varepsilon_{\mathrm{pl}}$ of the cross-tie. The present stress $\sigma$ is an obvious function of present strain $\varepsilon$ and present value of plastic strain $\varepsilon_{\mathrm{p} 1}$ :

$$
\sigma=\sigma\left(\varepsilon, \varepsilon_{\mathrm{pl}}\right),
$$

whereas the variation of plastic strain $\Delta \varepsilon_{\mathrm{pl}}$ can be expressed as a function of present strain $\varepsilon$, variation of present strain $\Delta \varepsilon$, as well as present value of plastic strain $\varepsilon_{\mathrm{pl}}$, in an 


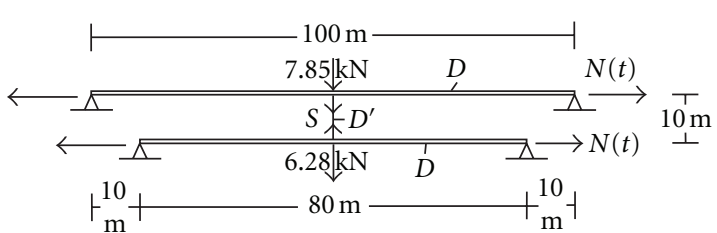

(a)

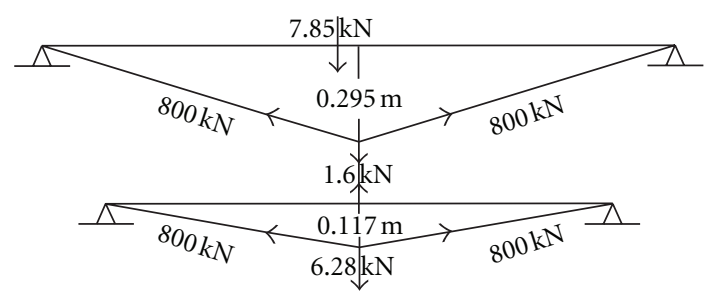

(c)

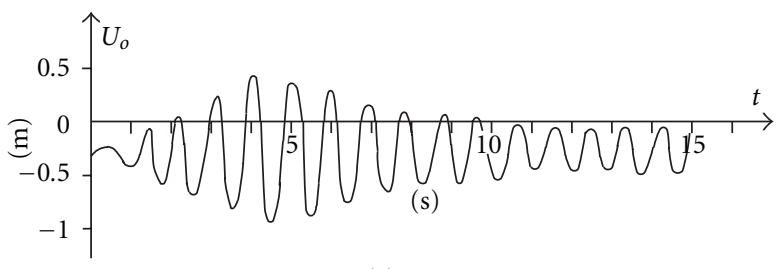

(e)

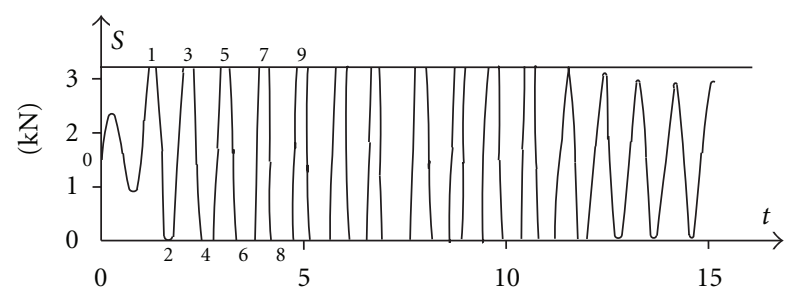

(s)

(g)

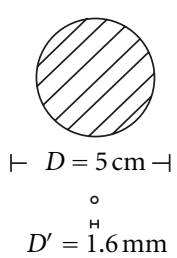

(b)

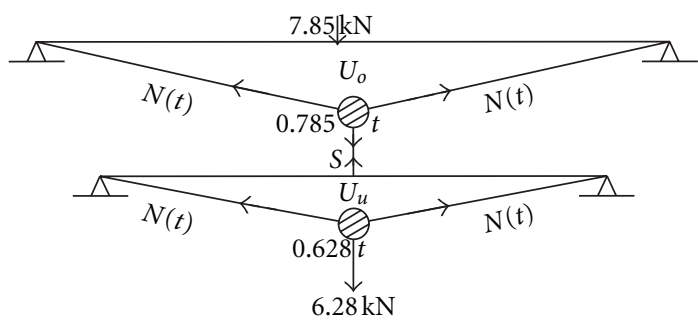

(d)

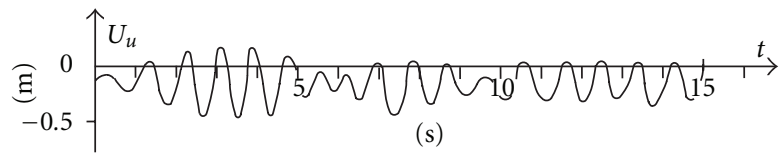

(f)

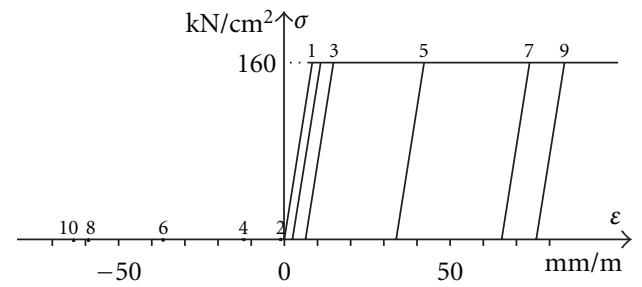

(h)

Figure 4: Second application: couple of interconnected cables, subject to traffic. (a) Given geometry and loading. (b) Crosssections of main cables and cross-tie. (c) Initial static analysis. (d) Parameters of dynamic analysis. (e), (f) Resulting time-histories of vertical displacements of centers of upper and lower cables. (g) Resulting time-history of axial force of cross-tie. (h) Resulting hysteresis stress-strain loops of the cross-tie.

obvious manner by the loading-unloading-reloading rule of Figure 2(b):

$$
\Delta \varepsilon_{\mathrm{pl}}=\Delta \varepsilon_{\mathrm{pl}}\left(\varepsilon, \Delta \varepsilon, \varepsilon_{\mathrm{pl}}\right)
$$

\subsection{Static Equations. The axial forces of the cross-ties are}

$$
\begin{aligned}
& S_{o}=\sigma_{\mathrm{o}} A_{w}, \\
& S_{u}=\sigma_{u} A_{w},
\end{aligned}
$$

for the upper and lower ties, respectively, where $A_{w}$ is the cross-section area of the very thin wires (cross-ties), whereas the vertical nodal forces applied at the centers of the cables, upper and lower one, respectively, are, according to Figure 2(a)

$$
\begin{gathered}
F_{o}=G_{o}-K_{G o} u_{o}+S_{o}, \\
F_{u}=G_{u}-K_{G u} u_{u}-S_{o}+S_{u},
\end{gathered}
$$

where the downwards direction has been taken as positive, $G_{o}$ and $G_{u}$ are weights at centers of upper and lower cables, respectively, and

$$
\begin{aligned}
& K_{G o}=2 \frac{N(t)}{l_{o} / 2}, \\
& K_{G u}=2 \frac{N(t)}{l_{u} / 2}
\end{aligned}
$$

are their geometric stiffnesses, where $N(t)$ is the given timehistory of the axial forces of the cables. 


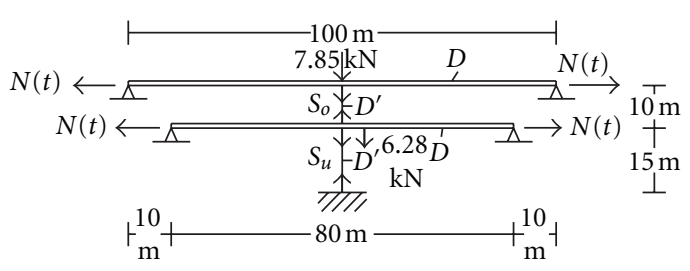

(a)

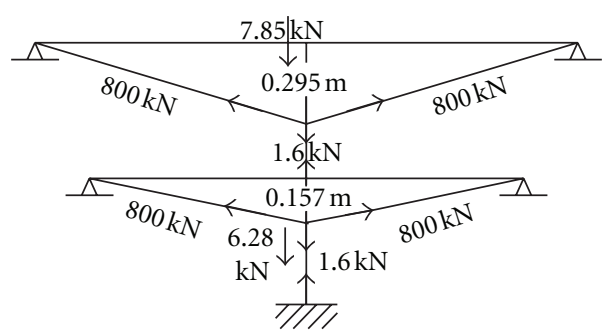

(c)

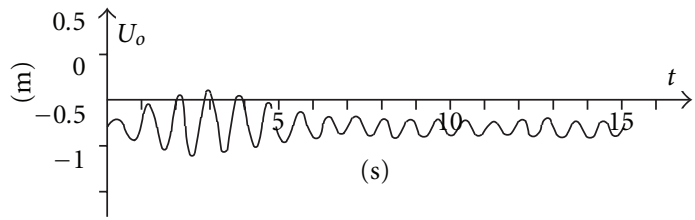

(e)

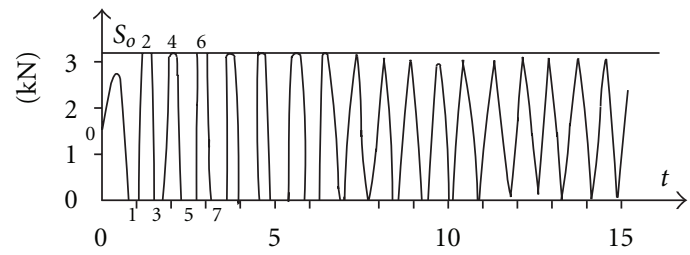

(s)

(g)

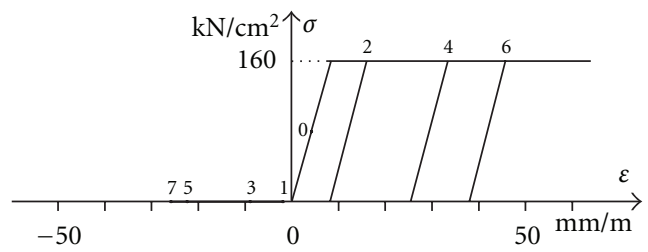

(i)

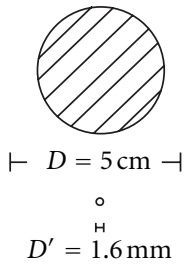

(b)

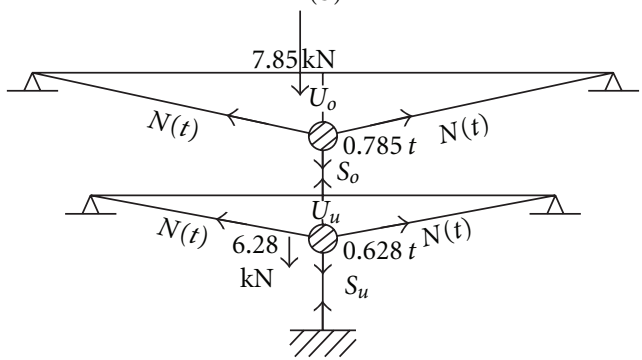

(d)

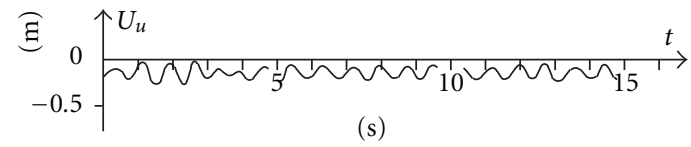

(f)

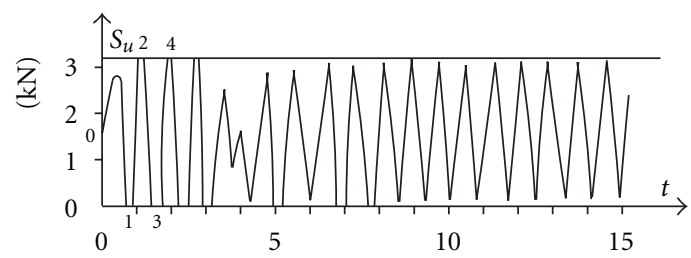

(s)

(h)

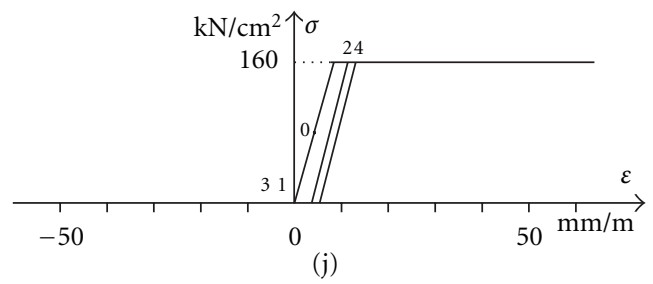

Figure 5: Third application: couple of cables, connected to each other and to deck, subject to traffic. (a) Given geometry and loading. (b) Cross sections of main cables and cross-ties. c. Initial static analysis. (d) Parameters of dynamic analysis. (e), (f) Resulting time-histories of displacements of upper and lower cables. (g), (h) Resulting time-histories of axial forces of upper and lower cross-tie. (i), (j) Resulting hysteresis stress-strain loops of upper and lower cross-ties.

2.4. Dynamic Equations. Damping is ignored, as the material internal friction of the cables is meaningless. The vertical accelerations at the centers of upper and lower cable are

$$
\begin{aligned}
& \ddot{u}_{o}=\frac{F_{o}}{m_{o}}, \\
& \ddot{u}_{u}=\frac{F_{u}}{m_{u}},
\end{aligned}
$$

where $m_{o}$ and $m_{u}$ are lumped masses at centers of cables (Figure 2(a)), whereas the upper dots mean derivation with respect to time.

2.5. External Excitation. Within the input data of the problem, the time-history of external excitation is given, which is here the variation of axial forces of cables due to traffic. The function $N(t)$ is assumed to be described by a piecewise 


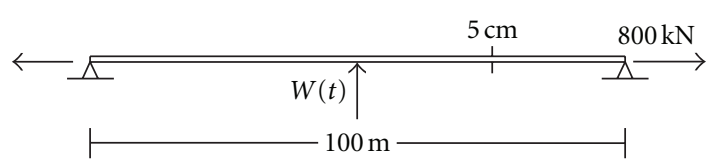

(a)

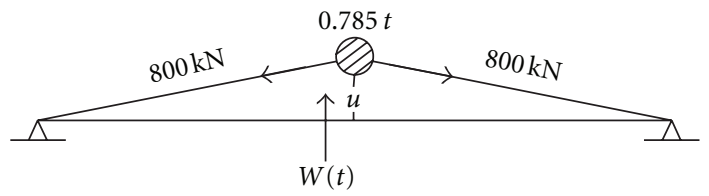

(b)

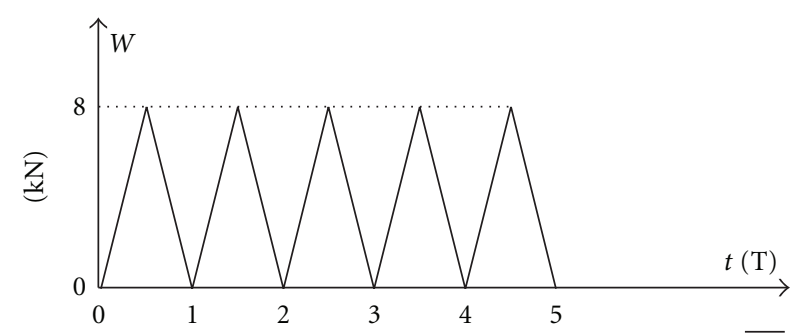

(c)

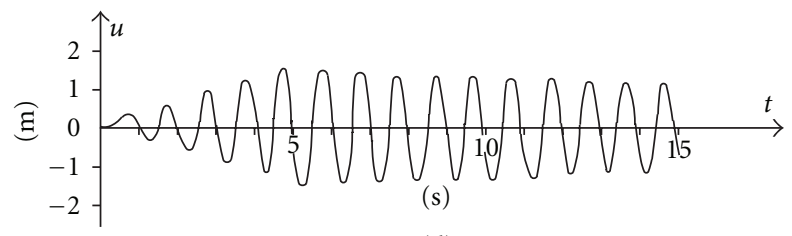

(d)

FIGURE 6: Fourth application: isolated cable subject to wind. (a) Given geometry and loading. (b) Parameters of dynamic analysis. (c) Given time-history of wind drag force. (d) Resulting timehistory of displacement of center of cable.

linear curve, as shown in Figure 2(c). And within each time interval, between two successive nodes, a linear interpolation is performed, in order to find, from a specific time instant $t$, the corresponding axial force $N$ of the cables.

\subsection{Initial Value Problem. A state vector is introduced:}

$$
\mathbf{y}=\{\mathbf{u} \mathbf{v} \mathbf{c}\}
$$

consisting of the vertical displacements $\mathbf{u}=\left\{u_{0} u_{u}\right\}$ (Figure 2(a)) and velocities $\mathbf{v}=\left\{\dot{u}_{o} \dot{u}_{u}\right\}$ of the centers of upper and lower cables, respectively, as well as of the constitutive variables $\mathrm{c}=\left\{\varepsilon_{o \mathrm{pl}} \varepsilon_{u \mathrm{pl}}\right\}$, which are the plastic strains (Figure 2(b)) of upper and lower cross-ties, respectively.

By combining all the previous equations, (1) up to (8), a system of first-order ordinary nonlinear differential equations is obtained:

$$
\dot{\mathbf{y}}=\mathbf{q}(t, \mathbf{y}),
$$

which, along with the initial value of the state vector

$$
\mathbf{y}(0)=\mathbf{y}_{\mathbf{o}}
$$

for time $t=0$, and with sought function the time-history of the state vector $\mathbf{y}(t)$, constitutes an initial value problem.
2.7. Proposed Algorithm. For the step-by-step dynamic analysis (direct time integration) of the previous initial value problem of $(9 a)$ and $(9 b)$, the algorithm of trapezoidal rule is proposed:

$$
\mathbf{y}_{n+1}=\mathbf{y}_{n}+\frac{1}{2}\left[\mathbf{q}\left(t_{n} \mathbf{y}_{n}\right)+\mathbf{q}\left(t_{n+1} \mathbf{y}_{n+1}\right)\right] \Delta t
$$

where $n$ and $n+1$ are two successive steps of the algorithm. This coincides with the algorithm of constant average acceleration of Newmark's group of algorithms for step-by step dynamic analysis.

The aforementioned algorithm is combined with a predictor-corrector technique, with two corrections per step, $\mathrm{PE}(\mathrm{CE})^{2}$, where, in this symbol, $P$ means prediction and $C$ correction of the state vector $\mathbf{y}$, whereas $E$ means evaluation of the function $\mathbf{q}(t, \mathbf{y})$ of $(9 \mathrm{a})$. In more detail, the proposed predictor-corrector technique can be written, within any $n$th step of the algorithm, as follows:

\section{Prediction}

$$
\mathbf{y}_{n+1}^{P}=\mathbf{y}_{n}+\mathbf{q}\left(t_{n} \mathbf{y}_{n}\right) \Delta t
$$

First correction

$$
\mathbf{y}_{n+1}^{1}=\mathbf{y}_{n}+\frac{1}{2}\left[\mathbf{q}\left(t_{n} \mathbf{y}_{n}\right)+\mathbf{q}\left(t_{n+1} \mathbf{y}_{n+1}^{P}\right)\right] \Delta t,
$$

\section{Second and final correction}

$$
\mathbf{y}_{n+1}=\mathbf{y}_{n}+\frac{1}{2}\left[\mathbf{q}\left(t_{n} \mathbf{y}_{n}\right)+\mathbf{q}\left(t_{n+1} \mathbf{y}_{n+1}^{1}\right)\right] \Delta t .
$$

Thanks to the aforementioned predictor-corrector technique, no solving of algebraic system is needed, within each step of the algorithm.

The stability criterion of the proposed algorithm is [9]

$$
\omega_{\max } \Delta t<2.0 \mathrm{rad}
$$

that is, $\Delta t<T_{\min } / \pi$; otherwise a divergent solution results, whereas the accuracy criterion is at least

$$
\omega_{\max } \Delta t<0.5 \mathrm{rad},
$$

that is, $\Delta t<T_{\min } / 4 \pi=T_{\min } / 12.56$; otherwise a significant accumulated truncation error appears, which is expressed as amplitude decay of the vibration, as well as period elongation.

\section{Computer Program}

Based on the proposed algorithm of previous Section 2.7, a simple and very short computer program has been developed, with only 115 Fortran instructions, consisting of the MAIN program (79 instructions) which performs the algorithm of step-by-step dynamic analysis, and of three subroutines: (1) Subroutine EVAL (17 instructions) which evaluates the present strain and stress state of the cable structure under consideration, (2) subroutine SE (9 instructions) 


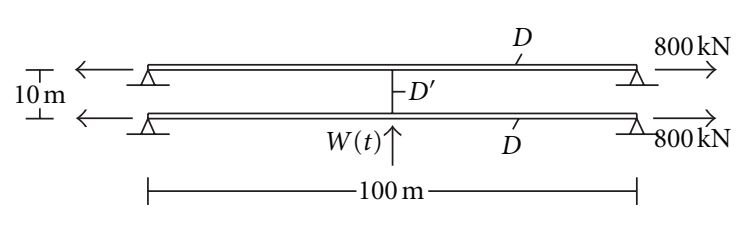

(a)

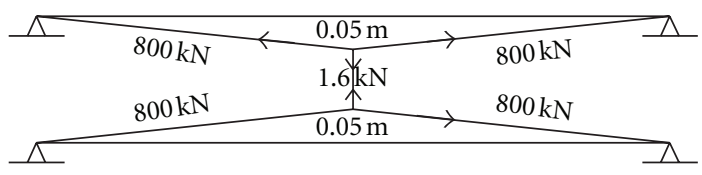

(c)

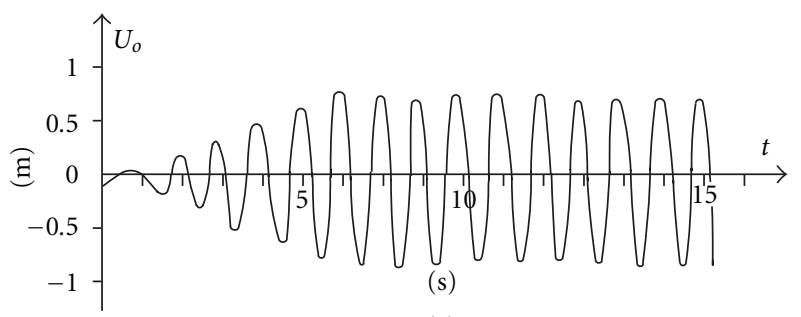

(e)

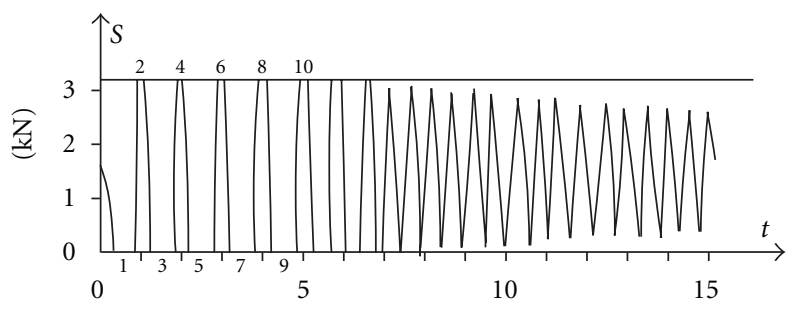

(s)

(g)

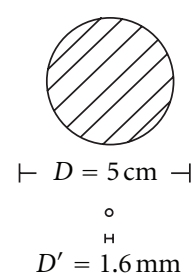

(b)

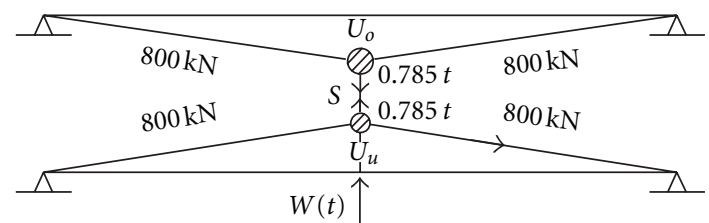

(d)

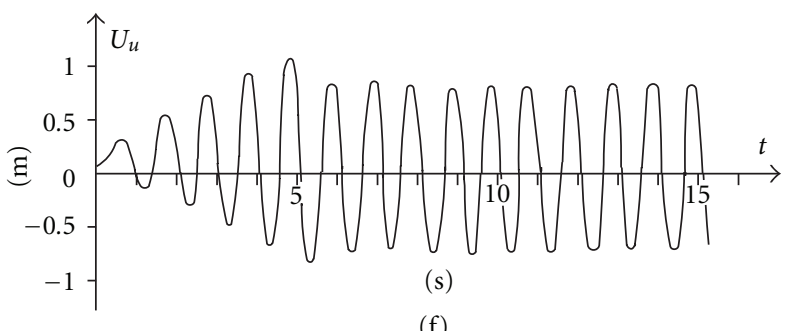

(f)

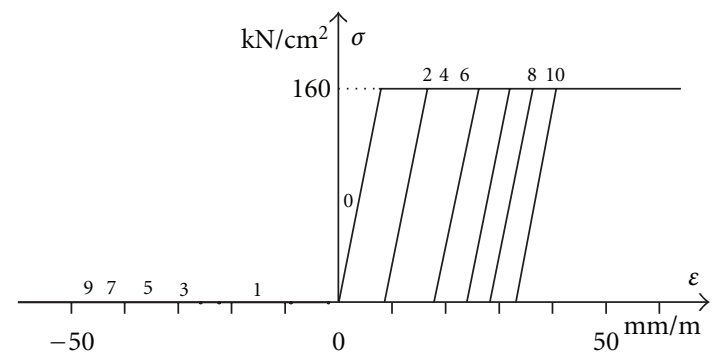

(h)

FIGURE 7: Fifth application: couple of interconnected cables subject to wind. (a) Given geometry and loading. (b) Cross sections of main cables and cross-tie. (c) Initial static analysis. (d) Parameters of dynamic analysis. (e), (f) Resulting time-histories of displacements of two main cables. (g) Resulting time-history of axial force of cross-tie. (h) Resulting hysteresis stress-strain loops of the cross-tie.

which describes the nonlinear uniaxial stress-strain law of a cross-tie, and (3) subroutine NHIST (10 instructions) describing the given time-history of the external excitation, which is, here, the variation, with respect to time, of the axial force of cables due to traffic.

A full documentation of the previous computer program is presented as Appendix, consisting of the description of program line by line in Section A.1, of the complete list of Fortran instructions in Section A.2, and the variables explanation in Section A.3. The documentation of the computer program is completed by the series of seven applications in Section 4 . The program is particularly oriented to the specific third application of Section 4.3, as already mentioned in the equations of problem in Section 2. However, by simple and obvious modifications of the computer program, all the other numerical experiments, in Section 4, can be treated, too.

\section{Applications (Numerical Experiments)}

Seven applications (numerical experiments) follow, on the dynamic analysis of isolated pretensioned cables of a cablestayed bridge or couples of parallel cables connected to each other and possibly with the deck of the bridge by very thin pretensioned single wires (cross-ties). Three of these cable structures are subjected to variation of axial forces of cables due to traffic (parametric excitation) and four of them are subjected to successive pulses of drag force due to a strong wind.

As already mentioned, the previously presented algorithm, in Section 2, is oriented only to the specific third application of Section 4.3. However, by simple and obvious modifications of this algorithm, all the other applications present in Section 4, which are presented herein after, have been analysed, too. 


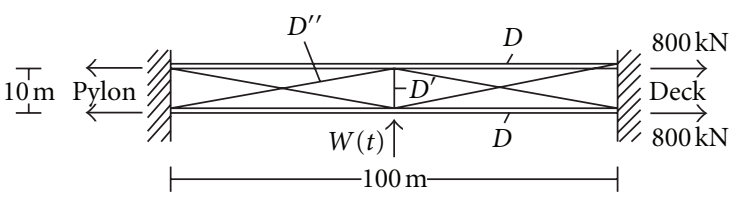

(a)

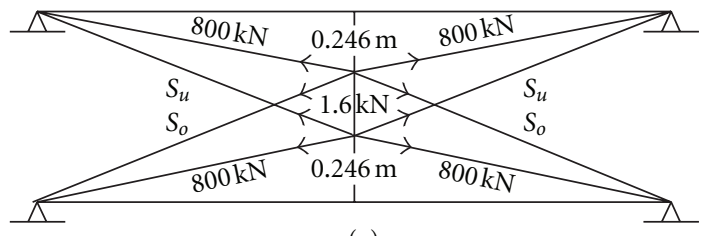

(c)

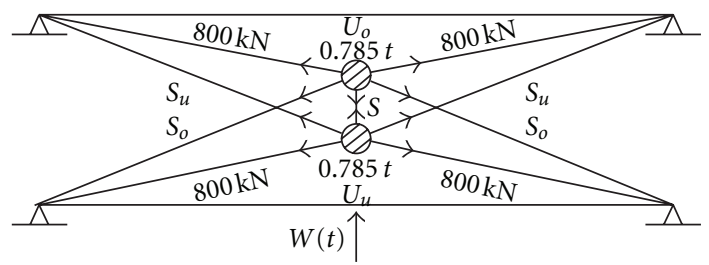

(d)

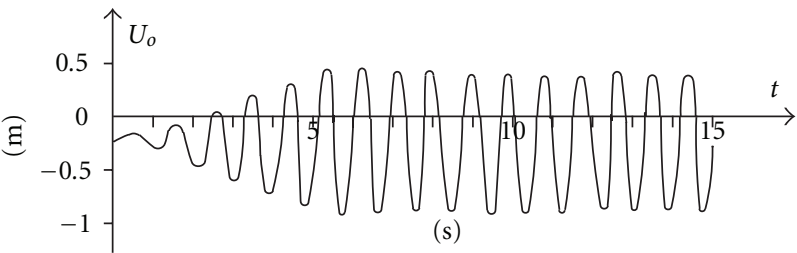

(e)

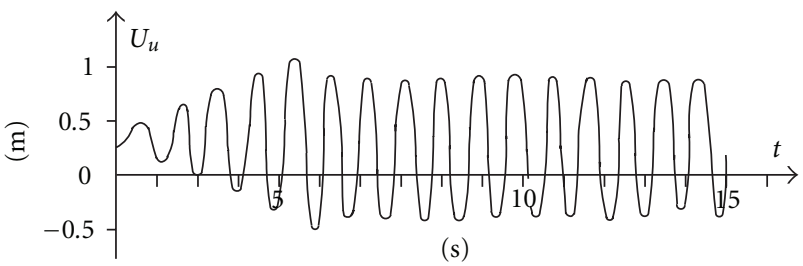

(f)

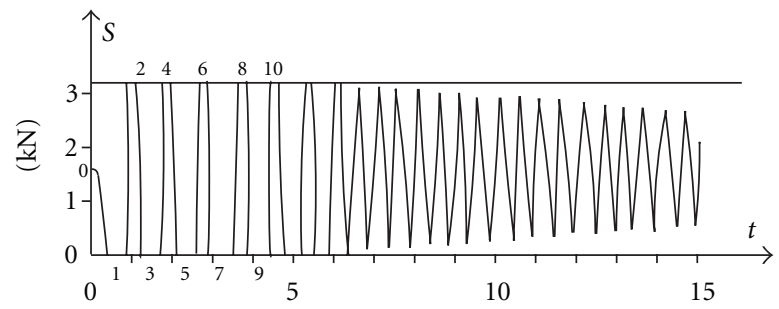

(s)

(i)

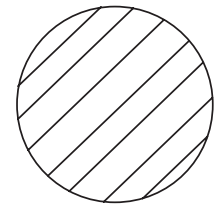

$\vdash D=5 \mathrm{~cm}-1$

$\mathrm{H}$

$D^{\prime}=1.6 \mathrm{~mm}$

O

$\mapsto$

$D^{\prime \prime}=0.5 \mathrm{~cm}$

(b)

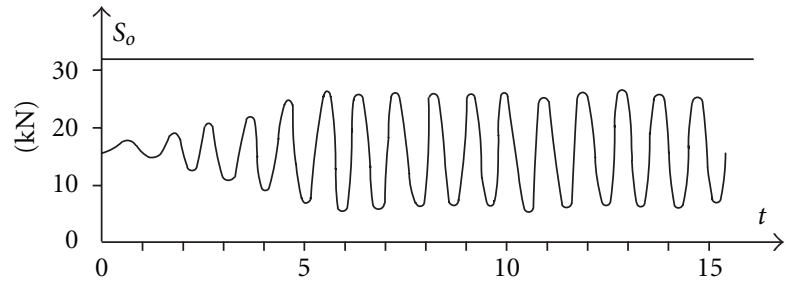

(s)

(g)

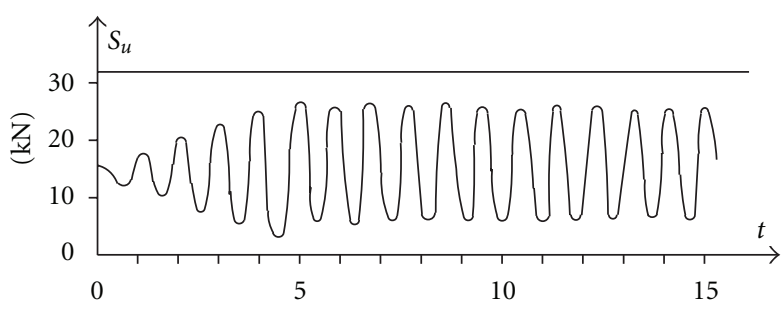

(s)

(h)

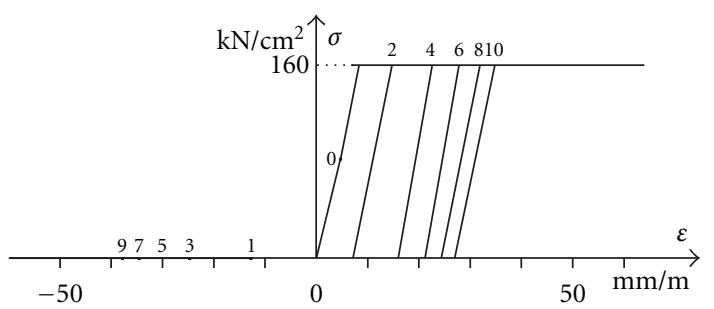

(j)

Figure 8: Sixth application: couple of cables interconnected by cross-tie, additionally connected by diagonals to pylon and deck, subject to wind. (a) Given geometry and loading. (b) Cross sections of main cables, cross-tie and diagonals. (c) Initial static analysis. (d) Parameters of dynamic analysis. (e), (f) Resulting time-histories of displacements of two main cables. (g), (h) Resulting time-histories of axial forces of diagonal bars. (i) Resulting time-history of axial force of cross-tie. (j) Resulting stress-strain loops of the cross-tie. 


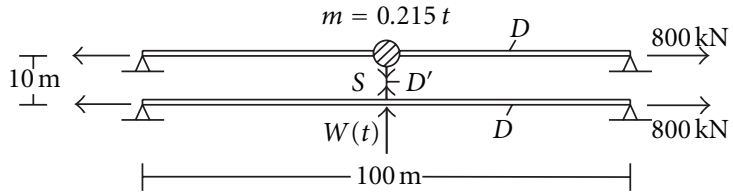

(a)

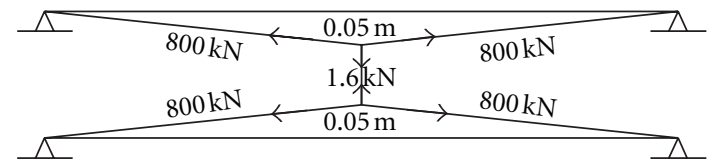

(c)

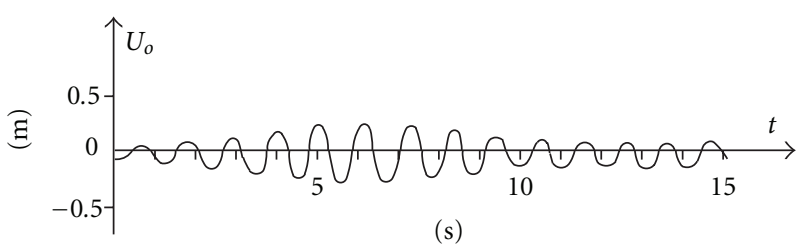

(e)

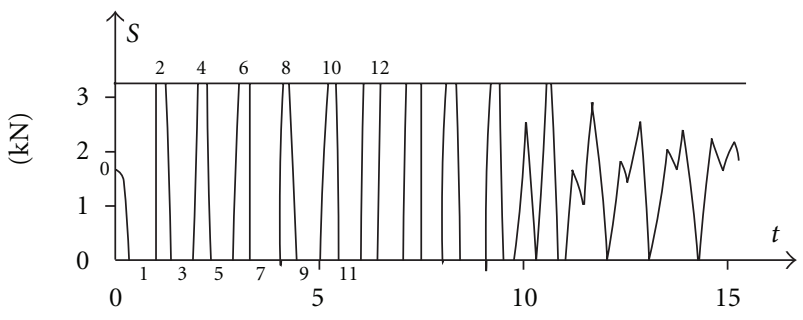

(g)

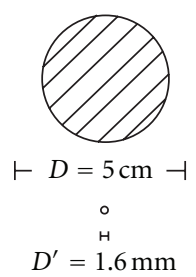

(b)

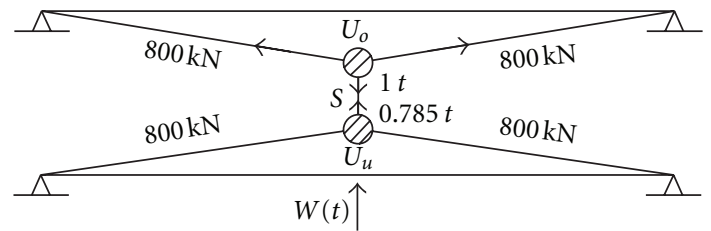

(d)

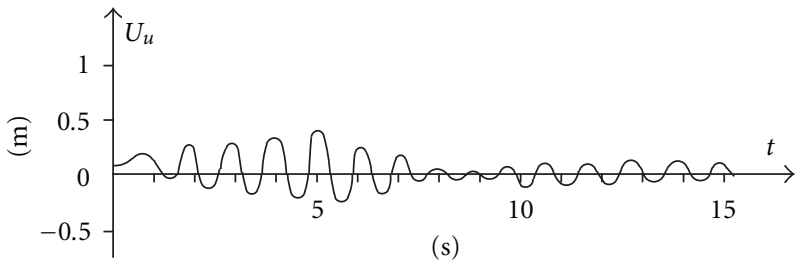

(f)

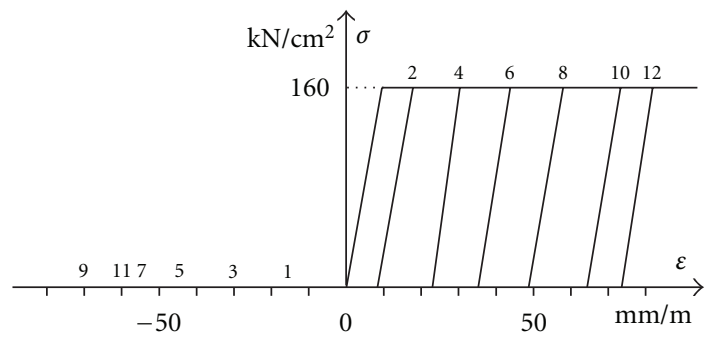

(h)

FIGURE 9: (a) Seventh application: Couple of inter-connected cables subject to wind with additional small mass on one cable. (a) Given geometry, loading and additional small mass. (b) Comparison of cross-sections of cables and cross-tie. (c) Initial static analysis. (d) Parameters of dynamic analysis. (e), (f) Resulting time-histories of displacements of two cables. (g) Resulting time-history of axial force of cross-tie. (h) Resulting hysteresis stress-strain loops of the cross-tie.

4.1. First Application: Isolated Cable Subject to Traffic. As shown in Figure 3, an isolated cable is subjected to a periodic variation of its axial force with a period equal to its fundamental one. Up to the fifth cycle that the excitation lasts, the vibration amplitude of the cable increases up to about $1.6 \mathrm{~m}$ and then remains constant; only a slight algorithmic damping is observed.

4.2. Second Application: Couple of Interconnected Cables Subject to Traffic. The cable of first application is, in Figure 4, connected to another shorter parallel cable by a thin crosstie. Both cables are subjected to a periodic variation of their axial force with a period equal to the fundamental one of the cable system. Up to the fifth cycle that the excitation lasts, the vibration amplitude of the upper cable increases up to $1.4 \mathrm{~m}$ and that of the shorter lower cable up to $0.7 \mathrm{~m}$. Then, both amplitudes are gradually reduced, the upper one up to $0.4 \mathrm{~m}$ and the lower one up to 0.3 , in $10 \mathrm{sec}$. Because of the different lengths of the two cables, thus different geometric stiffness, masses, and weights, too, large differences of displacements at the ends of the cross-tie are obtained, thus large stressstrain loops with a total width $\Delta \varepsilon \approx 76 \mathrm{~mm} / \mathrm{m}$, which are responsible for the significant hysteresis damping which is achieved.

4.3. Third Application: Couple of Cables Connected to Each Other and to Deck, Subject to Traffic. The cable system of the second application is, in Figure 5, supplied by one more thin cross-tie connecting the lower cable with the deck of the bridge. Because of the stiffness of this additional crosstie, the maximum vibration amplitudes of both cables are significantly reduced, that of the upper cable to $0.7 \mathrm{~m}$ and that of the lower cable to $0.3 \mathrm{~m}$. However, at same time, this reduction of displacements has a consequence less wide stress-strain loops in the upper cross-tie with total width $\Delta \varepsilon \approx 38 \mathrm{~mm} / \mathrm{m}$ and very thin stress-strain loops in the lower 
3

4

5

6

7

8

9

10

11

12

13

14

15

16

17

18

19

20

21

22

23

24

25

26

27

28

29

30

31

32

33

34

35

36

37

38

39

40

41

42

43

44

45

46

47

48

49

50

51

52

53

54

55

56

57

58

59

60

COMMON/A/AW, HO, HO0, DHO, EO, SO, TO, HU, HU0, DHU, *EU, SU, TU, WO, WU, N, LO, LU, FO, FU, MO, MU

COMMON/B/EY, ELAST

COMMON/C/NN, TK, NK

REAL LO, LU, MO, MU, N, NK

DIMENSION TK(20), NK(20)

$\operatorname{OPEN}(5, \mathrm{FILE}=$ "TIEIN.TXT")

OPEN (6,FILE= "TIEOUT.TXT")

READ (5,1)LO,LU,HO,HU,DC,DW,DENS

1 FORMAT(7F10.0)

$\mathrm{AC}=3.14159 * \mathrm{DC} * * 2 / 4$.

$\mathrm{MO}=\mathrm{DENS} * \mathrm{AC} * \mathrm{LO} / 2 . / 10000$.

$\mathrm{WO}=-\mathrm{MO} * 10$.

$\mathrm{MU}=\mathrm{DENS} * \mathrm{AC} * \mathrm{LU} / 2 . / 10000$.

$\mathrm{WU}=-\mathrm{MU} * 10$.

$\mathrm{AW}=3.14159 * \mathrm{DW} * * 2 / 4 . / 10000$.

READ $(5,1)$ SY,ELAST,SC0,SW0

$\mathrm{EY}=\mathrm{SY} / \mathrm{ELAST}$

$N=\mathrm{SC} 0 * \mathrm{AC}$

$\mathrm{TO}=\mathrm{SW} 0 * \mathrm{AW}$

$\mathrm{TU}=\mathrm{SW} 0 * \mathrm{AW}$

$\operatorname{READ}(5,2) \mathrm{NN}, \mathrm{TMAX}$

2 FORMAT(I5, F10.0)

$\operatorname{READ}(5,3)(\mathrm{TK}(I), \mathrm{NK}(I), I=1, \mathrm{NN})$

3 FORMAT(40F5.2)

$\mathrm{STIF} 1=2 . * N /(\mathrm{LO} / 2)+.\mathrm{ELAST} * \mathrm{AW} / \mathrm{HO}$

$\mathrm{STIF} 2=2 . * N /(\mathrm{LU} / 2)+.\mathrm{ELAST} * \mathrm{AW} / \mathrm{HO}+\mathrm{ELAST} * \mathrm{AW} / \mathrm{HU}$

$\mathrm{STIF} 12=-\mathrm{ELAST} * \mathrm{AW} / \mathrm{HO}$

$A=\mathrm{MO} * \mathrm{MU}$

$B=-(\mathrm{STIF} 1 * \mathrm{MU}+\mathrm{STIF} 2 * \mathrm{MO})$

$C=\mathrm{STIF} 1 * \mathrm{STIF} 2-\mathrm{STIF} 12 * * 2$

$D=\operatorname{SQRT}(\mathrm{B} * * 2-4 . * \mathrm{~A} * \mathrm{C})$

$W 1=\operatorname{SQRT}((-B+D) /(2 . * A))$

$W 2=\operatorname{SQRT}((-B+D) /(2 . * A))$

$T 1=2 . * 3.14159 / W 1$

$T 2=2 . * 3.14159 / W 2$

$\mathrm{DO} 4 I=1$, NN

$4 \quad \mathrm{TK}(1)=\mathrm{TK}(1) * \mathrm{~T} 2$

$\mathrm{DT}=T 2 /(4 . * 3.14159)$

$T=0$.

$\mathrm{UO}=(\mathrm{WO}-\mathrm{TO}) /(2 . * \mathrm{~N} /(\mathrm{LO} / 2)$.

$\mathrm{UU}=(\mathrm{WU}+\mathrm{TO}-\mathrm{TU}) /(2 . * \mathrm{~N} /(\mathrm{LU} / 2)$.

$\mathrm{VO}=0$.

$\mathrm{VU}=0$.

$\mathrm{EOPL}=0$.

$\mathrm{EUPL}=0$.

EW0 $=$ SW0 $/$ ELAST

$\mathrm{HO} 0=(\mathrm{HO}+\mathrm{UO}-\mathrm{UU}) /(1 .+\mathrm{EW} 0)$

$\mathrm{HU} 0=(\mathrm{HU}+\mathrm{UU}) /(1 .+\mathrm{EW} 0)$

CALL EVAL(UO,UU,EOPL,EUPL,GO,GU)

$5 \quad T=T+$ DT

$\operatorname{CALL} \operatorname{NHIST}(T, N)$

$\mathrm{UOP}=\mathrm{UO}+\mathrm{VO} * \mathrm{DT}$

$\mathrm{UUP}=\mathrm{UU}+\mathrm{VU} * \mathrm{DT}$

$\mathrm{VOP}=\mathrm{VO}+\mathrm{GO} * \mathrm{DT}$

$\mathrm{VUP}=\mathrm{VU}+\mathrm{GU} * \mathrm{DT}$

$\mathrm{EOPLP}=\mathrm{EOPL}$

$\mathrm{EUPLP}=\mathrm{EUPL}$

CALL EVAL (UOP, UUP, EOPLP, EUPLP, GOP, GUP)

$\mathrm{UO} 1=\mathrm{UO}+(\mathrm{VO}+\mathrm{VOP}) / 2 . * \mathrm{DT}$

$\mathrm{UU} 1=\mathrm{UU}+(\mathrm{VU}+\mathrm{VUP}) / 2 . * \mathrm{DT}$ 


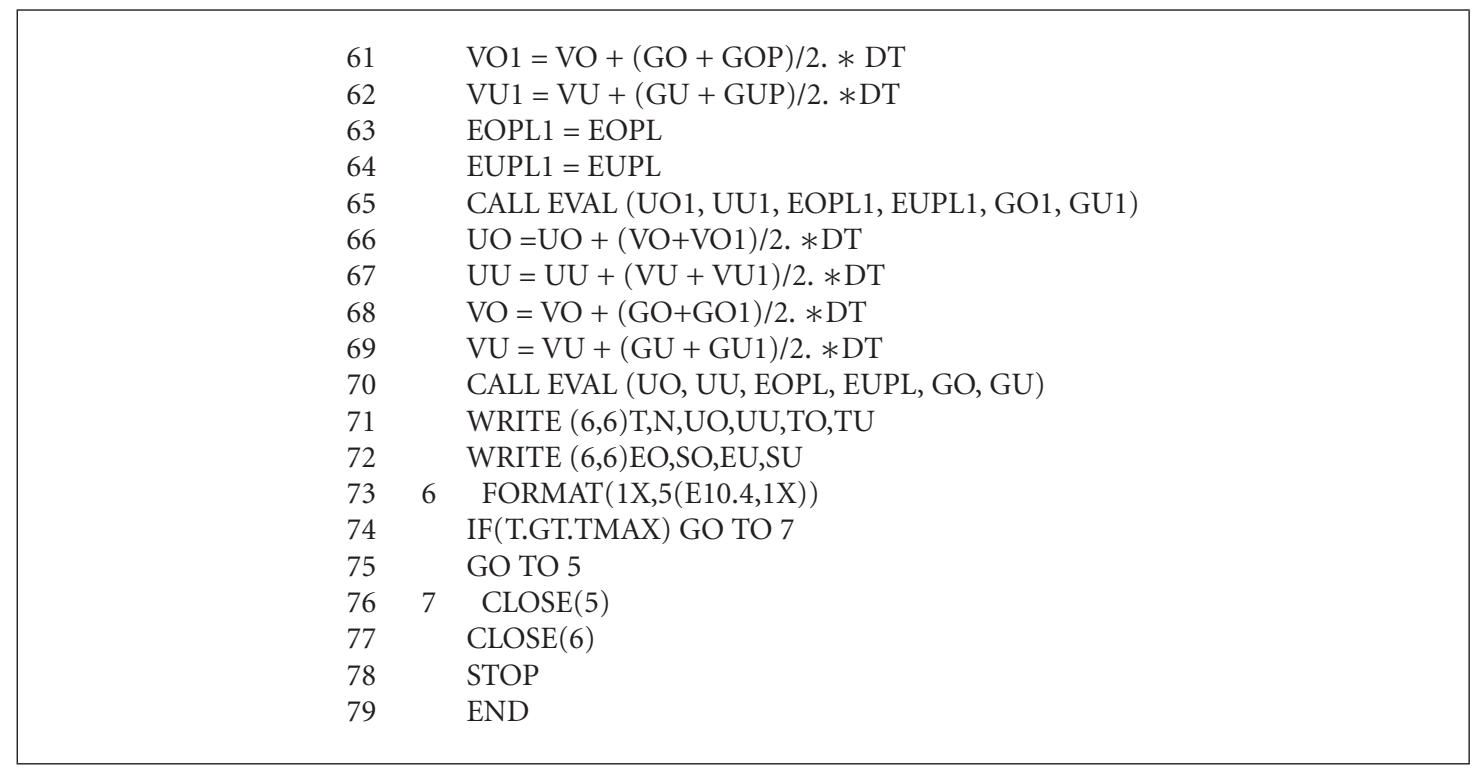

Algorithm 1: MAIN program.

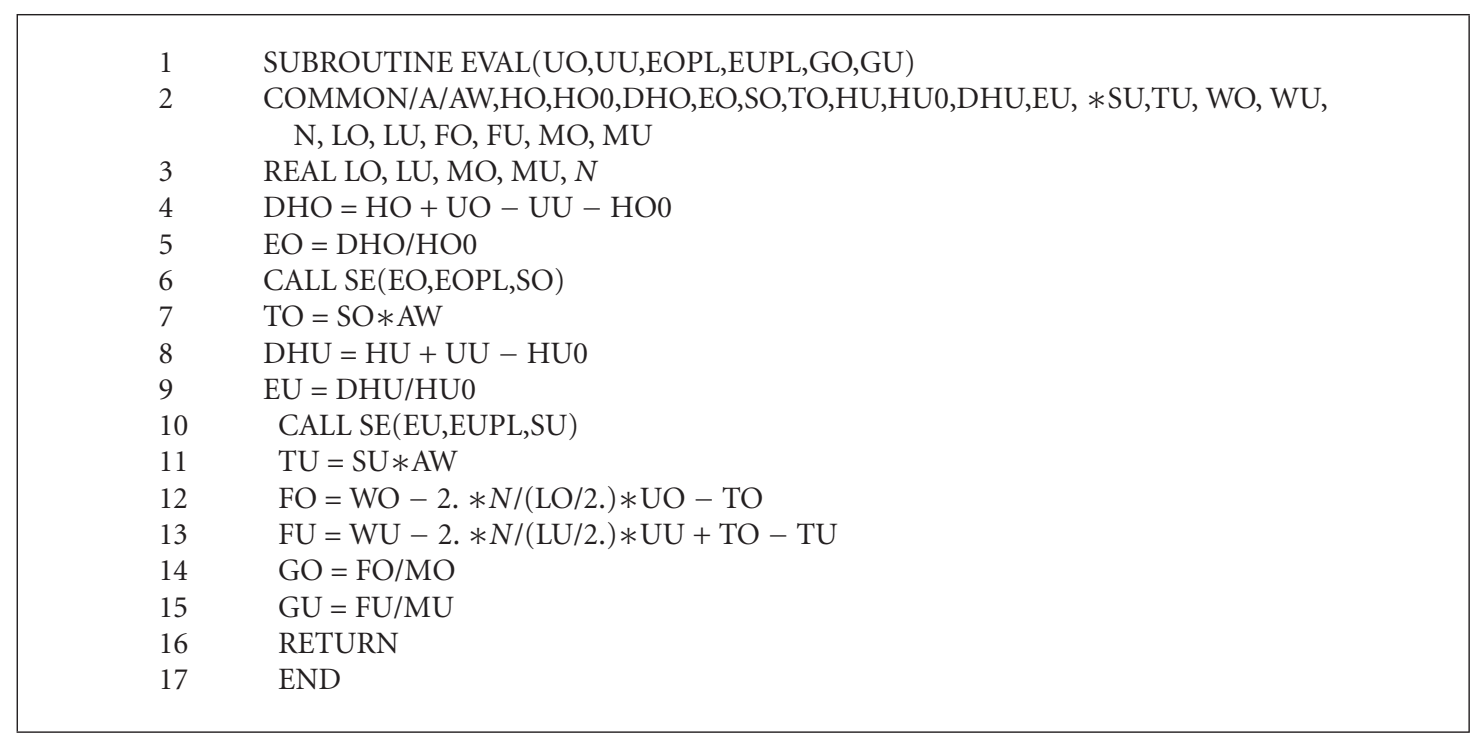

Algorithm 2: Subroutine EVAL.

\begin{tabular}{|ll|}
\hline 1 & SUBROUTINE SE(E, EPL, $S)$ \\
2 & COMMON/B/EY, ELAST \\
3 & IF(E,GT.EPL + EY)EPL=E-EY \\
4 & IF(E.LT.EPL)EPL=E \\
5 & IF(EPL.LT.0.)EPL=0. \\
6 & S = ELAST $*(E-$ EPL $)$ \\
7 & IF(S.LT.0.) $S=0$. \\
8 & RETURN \\
9 & END \\
& \\
\hline
\end{tabular}

Algorithm 3: Subroutine SE. 


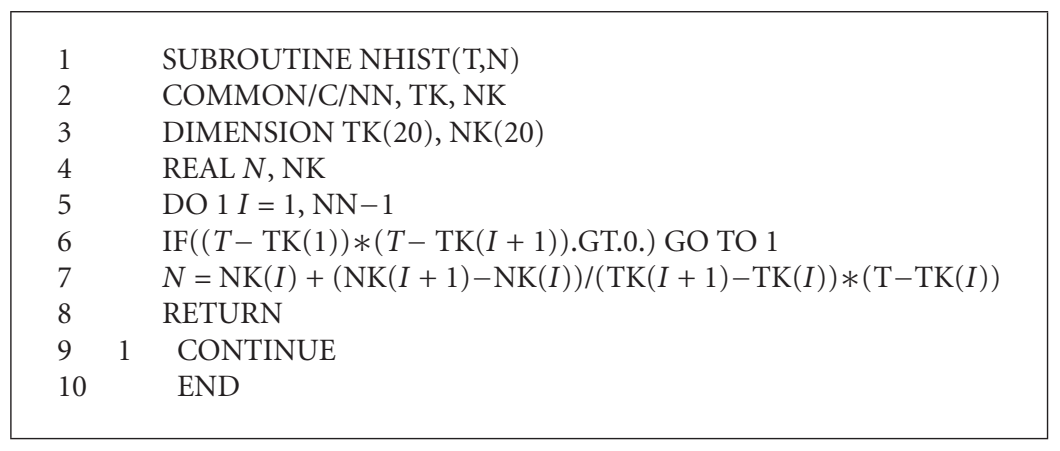

Algorithm 4: Subroutine NHIST.

cross-tie with only $\Delta \varepsilon \approx 6 \mathrm{~mm} / \mathrm{m}$, resulting in low values of hysteretic damping.

4.4. Fourth Application: Isolated Cable Subject to Wind. As shown in Figure 6, an isolated cable is subjected to a resonant periodic wind drag force. Up to the fifth cycle that the excitation lasts, the vibration amplitude increases up to about $3.0 \mathrm{~m}$ and then remains constant; only a slight algorithmic damping is observed.

4.5. Fifth Application: Couple of Interconnected Cables Subject to Wind. Two identical parallel cables are, in Figure 7, interconnected by a thin cross-tie. A wind drag force acts on one cable only; initially, this cable exhibits larger displacements, but gradually the movement is transferred to the other cable, too. So, the displacements are divided by two, compared with those of previous fourth application. During the initial stage of displacements transfer from one cable to the other, stressstrain loops of the cross-tie with a total width of medium size $\Delta \varepsilon \approx 33 \mathrm{~mm} / \mathrm{m}$ appear. From this point on, as the two cables are identical and perform similar movements, no more yielding of the cross-tie appears, as shown in Figure $7(\mathrm{~g})$, thus no more stress-strain loops and hysteretic damping, too.

4.6. Sixth Application: Couple of Interconnected Cables, Additionally Connected by Diagonals to Pylon and Deck, Subject to Wind. The cable system of the fifth application is, in Figure 8, supplied with diagonal ties connected with the pylon and the deck of the bridge. These diagonal ties offer a small additional stiffness, perpendicularly to the cables, which slightly reduces their displacements. However, at same time, this restriction of displacements further reduces the total width of stress-strain loops of the cross-tie to $\Delta \varepsilon \approx$ $27 \mathrm{~mm} / \mathrm{m}$, thus reducing the hysteretic damping.

4.7. Seventh Application: Couple of Interconnected Cables Subject to Wind, with Small Additional Mass on One Cable. The cable system of fifth application is in Figure 9, supplied by a small additional mass to the one of the two cables. So, the two cables have now different dynamic characteristics and they perform significantly different movements. As a consequence, large differences of displacements at the ends of the cross-tie result, thus wide stress-strain loops with a total width $\Delta \varepsilon \approx 73 \mathrm{~mm} / \mathrm{m}$, which implies significant hysteretic damping. The displacement amplitudes of the cables are now only about one-fourth of those of the fifth application.

\section{Conclusions}

Cable vibrations of cable-stayed bridges have been examined. Either isolated cables or couples of parallel cables, connected to each other and possibly with the deck of the bridge, by a very thin pretensioned wire (cross-tie), have been considered. External excitation is either traffic, which causes displacements of cable ends on deck and pylon, thus variation of axial forces, geometric stiffnesses and sags of cables, too (parametric excitation), or successive pulses of drag force due to a strong wind, perpendicularly to a vertical cables' plane at one side of the bridge.

The proposed analytical model is on the one hand simplified, as an SDOF oscillator is adopted for every individual cable, approximating its fundamental vibration mode. However, on the other hand, the proposed analytical model is accurate, as it takes into account the geometric nonlinearity of the cables by their geometric stiffness; also it includes the material nonlinearity of the cross-ties by their compressive loosening, tensile yielding, and hysteretic stressstrain loops.

The equations of the problem of dynamic analysis, oriented to a specific cable structure, have been written, consisting of the geometric, constitutive, static, and dynamic ones, as well as of the given time-history of the external excitation. By combining these equations, an initial value problem is obtained. For the step-by-step dynamic analysis of this problem, the algorithm of trapezoidal rule is proposed, combined with a predictor-corrector technique, with two corrections per step. So, no solving of algebraic system is required within each step of the algorithm.

Based on the proposed algorithm, a short computer program has been developed, with only 115 Fortran instructions, consisting of the main program and three subroutines. A full documentation is given for this program, which means transparency of computation.

Seven numerical experiments have been performed by the aforementioned program, three with variation of axial forces of cables due to traffic (parametric excitation) and four with successive pulses of drag force due to a strong wind. 
On the basis of previous series of numerical experiments some observations with practical usefulness are made. (These are not strict theoretical conclusions, but simple observations based on the results of numerical experiments.)

It is confirmed by the series of numerical experiments, the great advantage of pretensioned cross-ties, that although they are very thin, with ratio of cross-section area of a cable to that of a cross-tie of magnitude order 1000, however, they possess an axial elastic stiffness comparable in magnitude to the geometric stiffness of cables, with magnitude order $50 \mathrm{kN} / \mathrm{m}$, along the same direction, that is perpendicularly to cables axes.

The in-plane cross-ties (within a vertical cables plane) are intended to suppress cables' variations from parametric excitation due to traffic, whereas the out-of-plane cross-ties (transverse ones connecting cables at two sides of bridge) are intended to suppress cables vibrations from successive pulses of drag force due to a strong wind.

General observation from all numerical experiments: in a couple of parallel cables connected to each other and possibly with the deck of bridge by cross-ties, even a single cross-tie proves effective by its hysteresis damping (due to stress-strain loops) in suppressing large amplitude cable vibrations under the following circumstances: if the two cables have different dynamic characteristics, for example, different lengths which imply different masses, weights, and geometric stiffnesses, too, or if one of them has a small additional mass.

\section{Appendices}

\section{A. Documentation of the Proposed Computer Program}

In this appendix, documentation is given for the proposed computer program, for the step-by-step dynamic analysis of the third application, that of a couple of parallel cables connected to each other and to the deck of bridge by a thin cross-tie and subject to a variation of their axial forces.

A.1. Description of Program Line by Line. The description refers to the complete numbered list of Fortran instructions of Algorithms 1, 2, 3, 4 .

MAIN Program. The first seven lines include nonexecutable statements. Particularly, in the three first lines, the COMMON instructions connect the MAIN program with the three subroutines, by their common variables.

In the next 17 lines, 8 up to 24 , the input data are read: geometric data and density of steel in lines $8-9$, the parameters of $\sigma-\varepsilon$ law of steel along with the pretension stresses of cables and cross-ties in line 16, and the timehistory of axial forces of cables given by the coordinates of nodes of piecewise linear curve $N-t$ in lines $21-24$. In lines 10-15 and 17-20, some simple preliminary calculations are performed to determine cross-section areas and pretension forces of cables and cross-ties, as well as masses and weights of cables and yield strain of steel. In lines 25-35, the initial characteristic equation of the cable structure is solved, so that to find its natural frequencies and periods. In lines 36-37, the time scale of the given time history of external excitation is expanded so that to obtain a period equal to the fundamental one $T_{\max }$ of the structure, in order to cause resonance, whereas in line 38 , the minimum natural period $T_{\min }$ of the structure dictates the time-step length $\Delta t$ of the algorithm, so that to assure accuracy of computation.

In lines 39-49, the initial conditions are established: time $t=0$ in line 39 , determination of initial static displacements of cables in lines 40-41, evaluation of undeformed lengths of cross-ties in lines 42-44, zero initial velocities of cables in lines 45-46, zero initial plastic strains of cross-ties in lines 4748 , and evaluation of initial strain and stress state of structure by calling subroutine EVAL in line 49 .

In line 50, any step of algorithm begins by increasing time $t$ by $\Delta t$. In line 51 , by calling subroutine NHIST, the present value of axial force of cables is determined. In lines 52-55, the prediction of values of displacements and velocities is performed, and in lines $56-58$ by calling subroutine EVAL the corresponding plastic strains and accelerations are found. So in lines 52-58 the prediction of state vector within a step of algorithm is performed. In lines 59-65 the first correction of value of state vector is made by use of trapezoidal rule. And in lines 66-70, the second and final correction. In lines 7173 , the output data of present step of algorithm are written (time $t$, axial force $N$ of cables, displacements $u_{o}$ and $u_{u}$ of cables, axial forces $S_{o}$ and $S_{u}$ of cross-ties, strains and stresses $\varepsilon_{0}-\sigma_{0}$ and $\varepsilon_{u}-\sigma_{u}$ of cross-ties).

In lines 74-79 if a maximum time has been exhausted, the algorithm is interrupted. Otherwise, we continue to the next step of the algorithm.

Subroutine EVAL. Lines 1-3 are nonexecutable statements. In lines 4-7, from the displacements of cables, the elongation, strain, stress by calling subroutine SE, and axial force of upper cross-tie are determined. In lines 8-11, the corresponding quantities are found for the lower cross-tie. In lines $12-13$, the vertical nodal forces on centers of upper and lower cables are determined and in lines 14-15 the corresponding accelerations.

Subroutine SE. In lines 3-5, the new plastic strain of the cross-tie is found. In lines $6-7$, the stress of the cross-tie is determined.

Subroutine NHIST. In line 5 is found the time interval where present time $t$ is included. In line 6 , a linear interpolation is performed between the two end-nodes of the previous time interval, in order to find the axial force $N$ of cables corresponding to present time $t$.

\section{A.2. List of Fortran Instructions}

MAIN Program.

See Algorithms 1, 2, 3, and 4. 


\section{A.3. Variables Explanation}

\section{MAIN Program.}

$A=m_{o} \times m_{u}$ coefficient of characteristic equation

AC: cross-section area of a cable

AW: cross-section area of a wire (cross-tie)

$B=-\left(K_{11} m_{u}+K_{22} m_{o}\right)$ coefficient of characteristic equation

$C=K_{11} \times K_{22}-K_{12}^{2}$ coefficient of characteristic equation

$D=\left(b^{2}-4 a c\right)^{1 / 2}$ coefficient of characteristic equation

DC: cross-section diameter of a cable

DENS: density of steel

DHO: elongation of upper tie

DHU: elongation of lower tie

DW: cross-section diameter of wire (cross-tie)

$\mathrm{DT}=\Delta t$, time steplength of algorithm

ELAST: initial elasticity (Young) modulus

EO: strain of upper tie

EOPL: plastic strain of upper tie

EOPLP: prediction of EOPL

EOPL1: first correction of EOPL

EU: strain of lower tie

EUPL: plastic strain of lower tie

EUPLP: prediction of EUPL

EUPL1: first correction of EUPL

EVAL: subroutine for evaluation of strain and stress state of the structure

EW0: pretension strain of wires (cross-ties)

EY: yield strain of steel

FO: vertical nodal force at center of upper cable

FU: vertical nodal force at center of lower cable

GO: vertical acceleration at center of upper cable

GOP: prediction of GO

GO1: first correction of GO

GU: vertical acceleration at center of lower cable

GUP: prediction of GU

GU1: first correction of GU

HO: design (nominal) length (height) of upper crosstie

HO0: undeformed length (height) of upper cross-tie

HU: design (nominal) length (height) of lower crosstie

HU0: undeformed length (height) of lower cross-tie LO: length of upper cable
LU: length of lower cable

MO: mass of upper cable

MU: mass of lower cable

$N$ : axial force of a cable

NHIST: subroutine for given time-history of $N$

NK: ordinate of a node of piecewise linear curve $N-T$ $\mathrm{NN}$ : number of nodes of piecewise linear curve $N-T$ SO: stress of upper cross-tie

STIF1: $K_{11}$ elements of stiffness matrix

STIF2: $K_{22}$ elements of stiffness matrix

STIF12: $K_{12}$ elements of stiffness matrix

SU: stress of lower cross-tie

SW0: pretension stress of wires (cross-ties)

SY: yield stress of steel

T: time

TIEIN: input file

TIEOUT: output file

TK: abscissa of a node of piecewise linear curve $N-T$

TMAX: $t_{\max }$, maximum time of observation

TO: axial force of upper cross-tie

TU: axial force of lower cross-tie

T1: $T_{\min }$ extreme natural periods of structure ¡listitem $i j l a b e l / i$

T2: $T_{\max }$ extreme natural periods of structure

UO: vertical displacement of center of upper cable

UOP: prediction of UO

UO1: first correction of UO

UU: vertical displacement of center of lower cable

UUP: prediction of UU

UU1: first correction of UU

VO: vertical velocity of center of upper cable

VOP: prediction of $\mathrm{VO}$

$\mathrm{VO} 1$ : first correction of $\mathrm{VO}$

VU: vertical displacement of center of lower cable

VUP: prediction of VU

VU1: first correction of VU

WO: weight at center of upper cable

WU: weight at center of lower cable

$\mathrm{W} 1: \omega_{\max }$ extreme natural frequencies of the structure

W2: $\omega_{\min }$ extreme natural frequencies of the structure.

Subroutine EVAL. Only the following variable is different from those of MAIN program:

SE: subroutine for stress-strain law of a cross-tie. 
Subroutine SE. Only the following variables are different from those of MAIN program:

\author{
E: strain of a cross-tie \\ EPL: plastic strain of a cross-tie \\ $S$ : stress of a cross-tie.
}

Subroutine NHIST. All the variables are the same as in MAIN program.

\title{
References
}

[1] R. Walther, B. Houriet, W. Isler, P. Moia, and J. F. Klein, CableStayed Bridges, Th. Telford, London, UK, 2nd edition, 1999.

[2] E. Caetano, "Cable vibrations in cable-stayed bridges," IABSEStructural Engineering Documents, 2007.

[3] L. Caracoglia and D. Zuo, "Effectiveness of cable networks of various configurations in suppressing stay-cable vibration," Engineering Structures, vol. 31, no. 12, pp. 2851-2864, 2009.

[4] L. Caracoglia and N. P. Jones, "Passive hybrid technique for the vibration mitigation of systems of interconnected stays," Journal of Sound and Vibration, vol. 307, no. 3-5, pp. 849-864, 2007.

[5] L. Caracoglia and N. P. Jones, "In-plane dynamic behavior of cable networks. Part 1: formulation and basic solutions," Journal of Sound and Vibration, vol. 279, no. 3-5, pp. 969-991, 2005.

[6] L. Caracoglia and N. P. Jones, "In-plane dynamic behavior of cable networks. Part 2: prototype prediction and validation," Journal of Sound and Vibration, vol. 279, no. 3-5, pp. 993-1014, 2005.

[7] P. G. Papadopoulos, A. Diamantopoulos, P. Lazaridis, H. Xenidis, and C. Karayiannis, "Simplified numerical experiments on the effect of hysteretic damping of cross-ties on cable oscillations," in 9th International Conference on Computational Structures Technology, Athens, Greece, September 2008.

[8] P. G. Papadopoulos, J. Arethas, P. Lazaridis, E. Mitsopoulou, and J. Tegos, "A simple method using a truss model for in-plane nonlinear static analysis of a cable-stayed bridge with a plate deck section," Engineering Structures, vol. 30, no. 1, pp. 42-53, 2008.

[9] P. G. Papadopoulos, "A simple algorithm for the nonlinear dynamic analysis of networks," Computers and Structures, vol. 18, no. 1, pp. 1-8, 1984. 

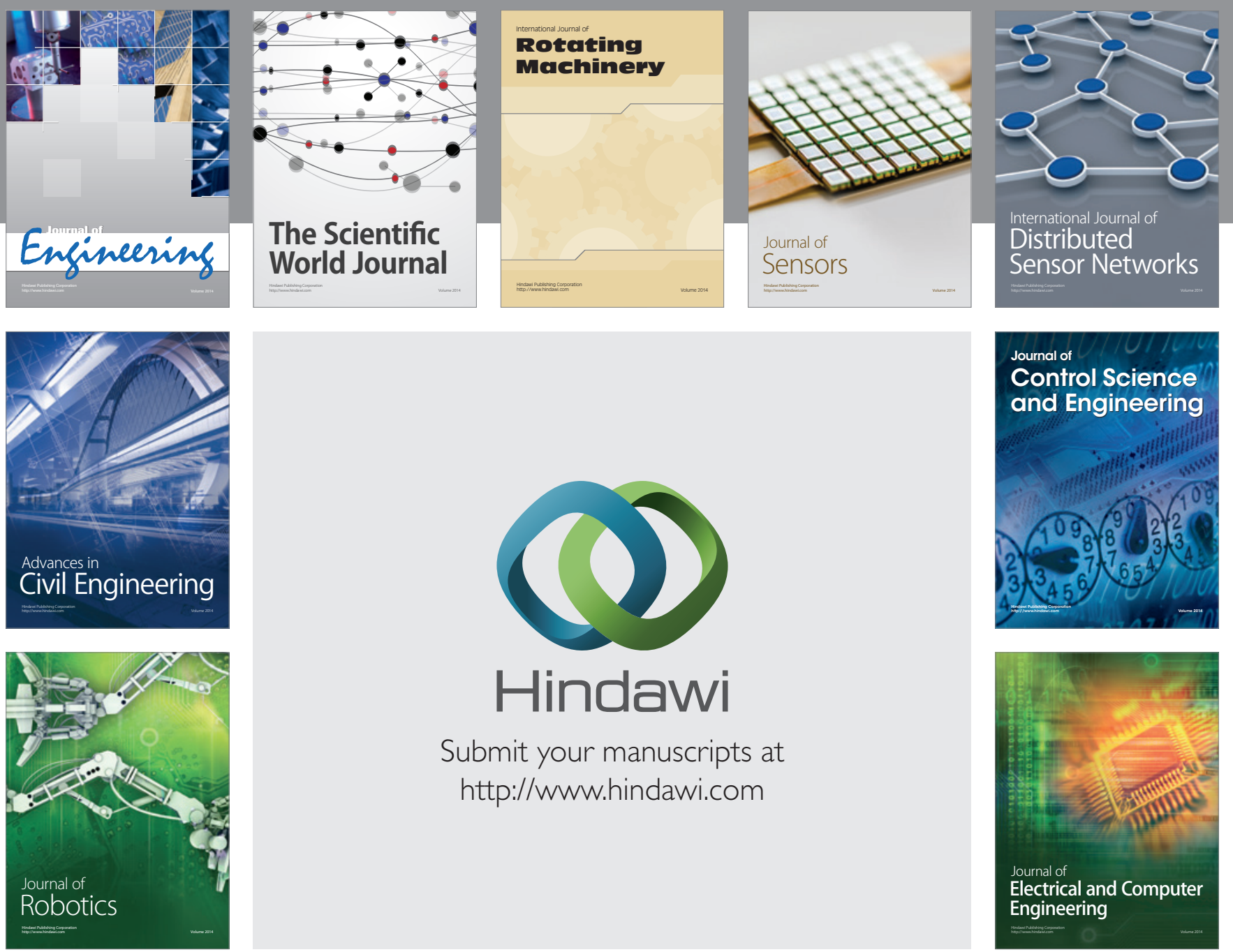

Submit your manuscripts at

http://www.hindawi.com
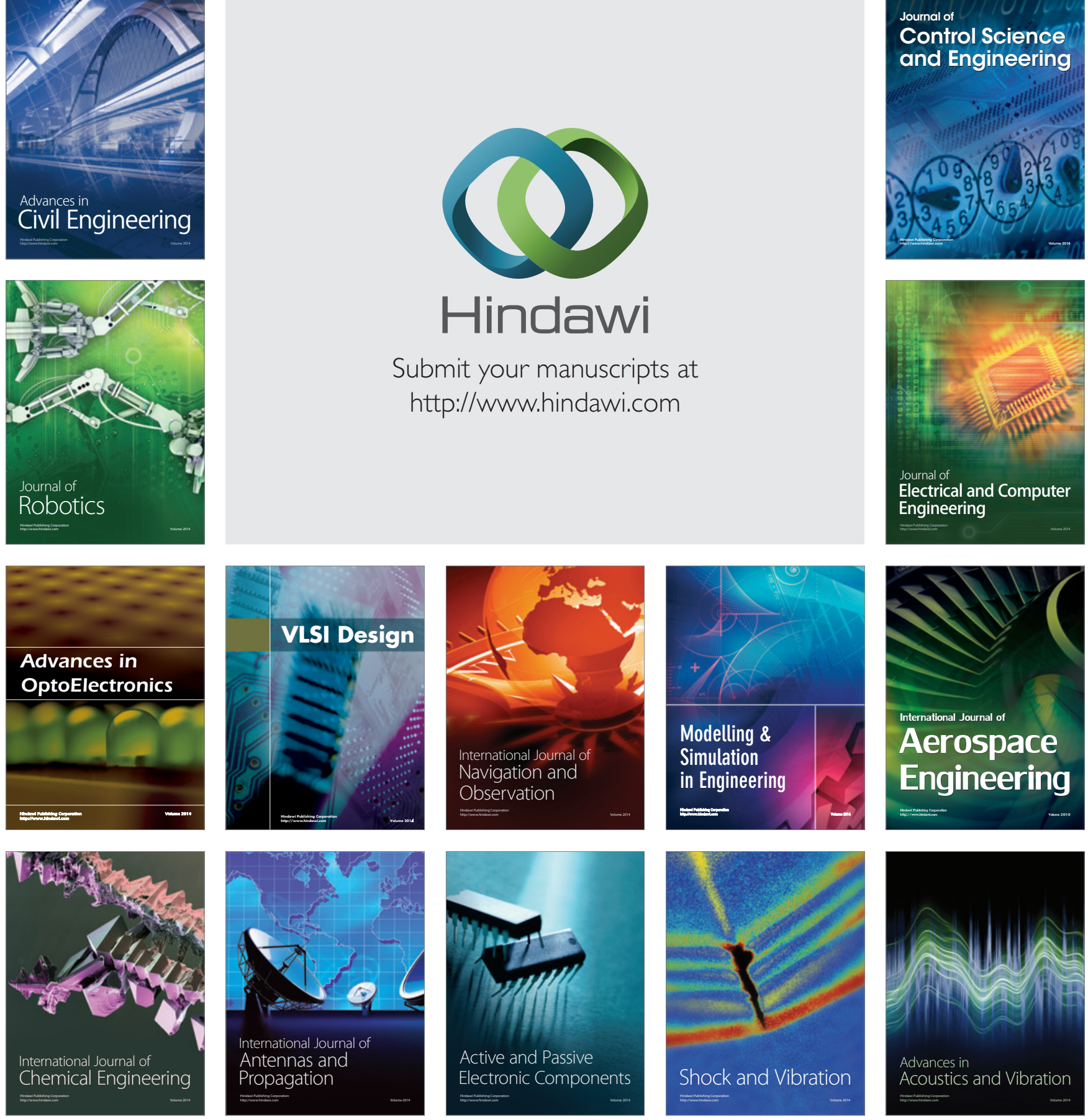